\title{
COMPETITIVE PRICING IN THE GOLF INDUSTRY
}

\author{
Cathy A. Enz \\ School of Hotel Administration \\ College of Business \\ Cornell University \\ 452 Statler Hall, Ithaca, NY 14853-6902 \\ E-mail: cae4@cornell.edu \\ Linda Canina \\ School of Hotel Administration \\ College of Business \\ Cornell University \\ 452 Statler Hall, Ithaca, NY 14853-6902
}

November 13, 2016

Cathy A. Enz is a Professor of strategy and holds the Lewis G. Schaeneman Professorship of Innovation and Dynamic Management in the School of Hotel Administration at Cornell University. Her research explores competitive pricing dynamics, knowledge creation, and service innovation. She received her Ph.D. from the Fisher College of Business at The Ohio State University.

Linda Canina is a Professor of Finance and the Richard J. and Monene P. Bradley Director of Graduate Studies in the Cornell Hotel School's Finance, Accounting, and Real Estate group. Her research interests include asset valuation, corporate finance, and strategic management. She holds a Ph.D. degree in finance from New York University. 


\title{
COMPETITIVE PRICING IN THE GOLF INDUSTRY
}

\author{
ABSTRACT \\ In this paper, we estimate the price elasticities of golf course demand, and then examine how pricing \\ relative to competitors further shapes demand (course utilization) and revenue per available tee time \\ round (RevPATR). Using a set of data for an entire destination golf market of 80 golf courses between \\ 2012 and 2014, we examined price elasticity by course quality tier, customer segments (i.e., player types), \\ month of the year, and day of the week. The sample used to calculate elasticities consisted of 140,567 \\ daily rounds of golf. The average daily rates were aggregated from transaction data based on over 2 \\ million rounds of golf booked annually in the market for the 3-year period. We find that during the entire \\ sampling period the demand for golf was primarily price inelastic, suggesting that a drop in price will not \\ have a significant positive impact on demand and revenue will decrease. Our examination of relative price \\ position using a sub-sample from 2013 revealed that courses that priced above their competition not only \\ reaped higher RevPATR, but also experienced higher daily course utilization. These finds suggest that \\ given price inelasticity in the golf market studied, higher priced golf courses are able to extract both a \\ revenue and a course utilization premium. Nevertheless, the full opportunity for maximizing revenue in \\ the market using revenue management techniques has yet to be exploited
}

\section{KEYWORDS}

price elasticity; golf demand; pricing in the service industry 


\section{INTRODUCTION}

Revenue management (RM) has been widely used in the hotel and airline industries, and widely understood to be relevant in the golf industry. Kimes and Schruben (2002), for example, noted that golf was a promising context for revenue management due to the perishable inventory of rounds of golf, the limited capacity of daily tee times available, and the ability to segment customers on price sensitivity. Beyond the recognition of suitability of golf to revenue management principles, the industry itself has become more intensely competitive. The rise of online intermediaries, flat demand, and oversupply have contributed to a growing interest in utilizing RM systems and more fully understanding competitive pricing (Enz and James, 2015; Douglass, 2014). In this paper, we focus on understanding pricing in the industry by first examining price elasticities of demand for a large competitive golf market, and secondly by exploring the dynamics of competitive pricing by comparing relative price positions, rounds of golf played, and revenue per available tee time round (RevPATR) for golf courses in an entire competitive market. The purpose of this research is to begin understanding competitive pricing in the golf industry in the hopes of helping this sector better use data to introduce RM systems and more fully optimize pricing.

\section{THE LITERATURE ON GOLF REVENUE MANAGEMENT}

Research on revenue management within the golf industry has been limited and focused on a select group of topics. In particular, capacity control has been a popular topic of exploration in efforts to determine tee time intervals or pace of play (Rasekh and Li, 2009; Licata and Tiger, 2010; Kimes and Schruben, 2002). Another body of literature has examined pricing and price discrimination in golf settings with a focus on peak load pricing (Limehouse et al, 2010, 2012). Limehouse et al (2012) found that both peak-load and price discrimination are evident in the golf industry, but market competition reduces peak time price premiums. This work raises important questions about the impact of competition on pricing. Another study within the golf context found that golf customers viewed varying price levels as an extremely unacceptable practice, while other revenue management practices, such as coupons, and tee time interval pricing were viewed as acceptable (Kimes and Wirtz, 2003). Given the sensitivity of golfers 
to varying prices, the declining demand for golf in the US market, and the role of competition, it is not surprising that the golf industry has been reluctant to adopt dynamic (flexible) pricing and has also sought to discount to stimulate demand. Further, little is actually known about price elasticity of demand in the industry, making the pricing of golf a truly challenging task. In this study, we begin by estimating and comparing the price elasticities of golf course demand for 80 courses in a Southeastern US destination from January 2012 through May of 2014. We use a consistent set of data and models because elasticity estimates vary according to data type and empirical model specification (Hughes et al, 2007; Espey, 1998).

\section{COMPETITIVE PRICING}

Historically in the golf industry, managers established seasonal static rates and hoped to maximize available capacity at the predefined rates. With flat demand for golf, excess supply of golf courses, and the rise in online third-party booking channels, golf consumers are increasingly forming their price expectations based on the competitive pricing environment, which includes the prices paid to golf at similar quality golf courses in the same destination market (Enz and James, 2015). Cognitive benchmarks or memories of past prices, along with repeated play or recent purchases from competitor courses contribute to a competitive "reference price effect"' often called external reference prices when referring to those outside of the individual consumer's memory (Greenleaf, 1995). A body of literature exists that has found reference pricing to shape consumer purchase decisions (Melnikov, 2015; Anderson et al, 2005). While the reference price effect has been examined extensively over the last two decades, particularly using simulations to help managers find optimal pricing strategies, it has not been explored in a golf context (Greenleaf, 1995; Kachanil et al, 2014).

The price patterns that consumers see within a given competitive market when they compare the fees for a round of golf among comparative courses should impact decision choices, and influence course capacity utilization. Recent work such as Zhang (2014) found that it was more beneficial for consumers to have a higher initial reference price, particularly when studying reference pricing in a distribution channel 
context. In this study, we explore the impact on course capacity utilization and revenue of a decision to price golf above or below the prices set by competitors. In recent years, many golf course owners have discounted their rounds of golf in the hopes of stealing market share and lifting their daily course capacity utilization. Recognizing the impact that competitors' prices can have on demand and associated revenues, recent RM research and practice has sought to incorporate competitor price information (Noone et al, 2012).

Beyond the reference price effect literature, a diverse literature (for an overview see Gallego and Hu, 2007) has emerged exploring RM under competition (see Mookherjee and Friesz, 2008; Perakis and Sood, 2006; Levin et al, 2009). Lieberman (2004) suggests that incorporating competitor prices into RM models will facilitate RM systems’ responsiveness to a firm’s strategic price positioning policies. Bolton and Shankar (2003) indicate that relative price position - higher or lower than, or on par with, the competition - is a key dimension of strategic pricing.

In the hotel context, a variety of studies have examined the price positioning-revenue per available room (RevPAR) relationship in the context of the U.S. and European hotel markets, finding that hotels that price above their direct competitors generate higher relative RevPAR, but with lower capacity utilization or occupancy (Enz et al, 2009; Enz and Canina, 2010). Chung (2000) reported that price cutting in Seoul hotels did not allow firms to gain greater market share, even during off-peak periods. She concluded that pricing at higher levels serves the dual purposes of maintaining the market share of every hotel and increasing total revenue of the market as a whole. While preliminary research in the golf context would suggest that increased competition shapes price variability, and reference price effects are likely, the second purpose of the current study is to explore competitive pricing dynamics in a golf destination resort market.

\section{RESEARCH QUESTIONS}

The research questions of interest in this study are whether demand for golf is price elastic, and what the impact of competitive comparative pricing is on revenue and capacity. In particular, we will 
develop models to estimate price elasticity, and then examine competitive pricing. We explore whether those golf courses that price above their competitors (higher average daily fees - ADFs) will have lower demand in the form of capacity utilization and lower overall revenue per available tee time round (RevPATR). We focus our attention on a popular and large golf destination with daily public-use golf courses catering to both package and walk-in customer segments.

\section{METHODOLOGY}

\section{Sample}

The data used in this study were obtained from a central tee time reservation system shared by all 80 golf courses in the destination for the period from January 2012 to May 2014. The number of rounds of golf booked by both package and walk-in customer segments during the study period were as follows: (1) 2,822,249 rounds in 2012, (2) 2,781,123 rounds in 2013, and 2,809,227 rounds in 2014. Data were obtained from the destination tee time reservation booking engine for each player transaction with the endorsement and support of the local chapter of the National Golf Course Owners Association. For purposes of this study, the millions of rounds of golf were aggregated to arrive at a sample of 140,567 daily rounds of golf (80 courses 93 years 92 customer segments 9 number of days of the year golf was played in 2012-2014). Price is the average daily fee for a round of golf, which includes both greens fee and cart fee.

The data provider supplied the following variables: the date and time of the round; the greens fee; the cart fee; the customer segment (e.g., package player, walk-in player, and course member) the commission paid to intermediaries; and, the status of the round (played, cancelled or no show).

Additionally, the data provider supplied several course characteristics measures including location in the market (North, Central, and South), the slope of the course, the rating of the course, the PAR of the course, whether or not water features exist on the course, and whether or not a hotel was located next to the course. The courses in the market were segmented by the owner's association into 4 approximately equal competitive quality grouping or tiers of around 20 golf courses in each tier. The tiers are based on 
the attributes of the courses such as the existence of a practice range, golf instruction from a professional golf association (PGA) member, food and beverage facilities, year built, special course design features, regular tee time PAR, and the PGA rating and slope of each course. Given that the weather conditions (e.g., rain, frost, excessive hot or cold) can change the number of rounds of golf available on a given day, we obtained daily measures of precipitation, temperature, and frost for the year, for each of the three market locations; north, central, and south. The total rounds of golf available on each day of the year were calculated taking into consideration the weather conditions on the day of play. A total of 94.1 per cent of total days were playable, and 92 per cent of the days had 8 or more playable hours in 2013. In addition, 68.7 per cent of the rounds of golf booked (3,176,655 rounds) were on days without rain.

The demand and price variables were aggregated to a daily level by customer segment (i.e., package and walk-in player types). The demand by customer segment was the sum of the number of rounds booked by segment by day. The price paid by customer segment was the daily total revenue received from the segment divided by the total rounds of golf booked by the segment players.

For the second stage of the study, the sample included all rounds of golf for all 80 golf courses in the market during 2013. Individual rounds of golf were aggregated by customer segment to arrive at the average daily fee for each day of the year, daily RevPATR, and daily capacity utilization.

\section{Price elasticities model specification}

The econometric models used in this paper reflect the most important market and golf course characteristics as defined by interviews with ten golf course owners and advisory board members of the destination's course owners' association. The models include variables viewed as essential in previous studies of golf course pricing (Limehouse et al, 2012). The models were estimated by customer segment, golf course competitive tier, month of the year, and day of the week. Our base model specifies the log of rounds of golf as a function of the log of average daily price. Specifically, we estimate 


$$
\begin{aligned}
1 \mathrm{n}(\text { Rounds })_{j p t} & =\beta_{0}+\beta_{1} 1 \mathrm{n}(\text { Price })_{j p t}+\beta_{2}(\text { Age })_{j}+\beta_{3}(\text { Rating })_{j} \\
& +\beta_{4}(\text { Slope })_{j}+\beta_{5}(\text { Number of Holes })_{j}+\beta_{6}(\text { RegTeePAR })_{j} \\
& +\beta_{7}(\text { Water Features })_{j}+\beta_{8}(\text { Lodging })_{j} \\
& +\beta_{9}(\text { Minimum Temperature })_{r t} \\
& +\beta_{10}(\text { Precipitation })_{r t}+\beta_{11}(\text { North })_{j}+\beta_{12}(\text { Central })_{j}
\end{aligned}
$$

where $j$ represents the course, $p$ represents the customer segment, $r$ represents the regional location, and $t$ represents the day of the year. Rounds $s_{j p t}$ is rounds of golf by segment $p$ for course $j$ on day $t$, Price $e_{j p t}$ is the average daily price of a round of golf by segment $\mathrm{p}$ for course $j$ on day $t$. The other variables in the model included the following: Age ${ }_{j}$ the age of the course, Rating $j_{j}$, the rating of the course, Slope $\mathrm{j}_{j}$, the slope of the course, Number of Holes $j$, number of holes of golf available for play at course $j$ on day $t$, RegTeePar $j$, regular tee PAR for the course, Water Features $j$, whether the course has a notable water feature, Lodging , whether the course has adjacent lodging, Minimum Temperature for Day $r$, the minimum temperature in degrees Fahrenheit for day $t$ in region $r$, Precipitation for Day, the precipitation

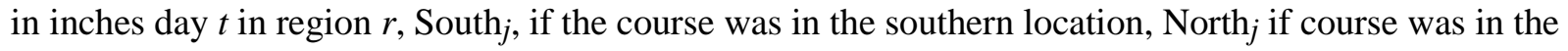
northern location, and Central $j$, if the course was in the central location. Note that the Southern location was used as the reference group and was omitted from the estimated models. The double-log functional form is a common specification used in elasticity studies, and is used here because it provides a good fit to the data and allows for consistency with previous studies.

Since the data set consists of panel data, both time series for each course and cross-sectional across courses, the errors are serially correlated. As a result, we estimated the standard errors correcting for serial correlation by clustering on the golf course. In addition, we included a fixed effect for the year. 


\section{MEASURES FOR COMPETITIVE PRICING IN 2013}

Daily capacity utilization was calculated as the number of rounds played by customer segment by day divided by the total number of rounds available to be played by day. The total number of rounds available to be played each day varied depending upon the weather.

Average daily fee (ADF) was computed by taking the total fees paid by customer segment by day divided by the number of rounds played by customer segment. Both cart fee and greens fee were included in the total fee measure. Cart usage is often bundled into the price of a greens fee, particularly for package players, making the distinction between pricing with or without a cart less relevant in this destination market. We conducted preliminary analyses for greens fees only and for greens fees plus cart fees, and found that the use of a cart did not alter the results. Given that many courses require the use of a cart, and others include the price of the cart in their greens fee our measure of total fees paid included both cart and greens fees together. In consultation with the golf course owners' association, and the third party data provider, the approach of combining cart and greens fees was deemed the most appropriate approach to accurately capture daily fee.

Daily Revenue per available tee time round (RevPATR) was computed by taking the total fees paid by day by customer segment divided by the total number of rounds available to be played by day by customer segment.

The competitors for each course were defined by the market as those courses in the same quality grouping or tier. Given the four tiers, approximately 18-21 competitive courses were used to make reference pricing comparisons. The final sample size for this portion of the study was 26,916 observations (80 courses 9 number of playable days) for the year 2013.

Reference Pricing was computed for each day of the sample period. Our daily pricing strategy measure was the percentage difference in ADF by customer segment for each course and its competitive set of same tier courses. In order to address the possibility that lower priced courses in the same competitive set are not as desirable, we only included those observations in which the daily number of rounds was within one standard deviation of the average number of daily rounds across all courses with 
the same competitive tier group. This approach helps to mitigate the possibility that lower priced golf courses in the same competitive set have lower demand. We used the percentage difference in ADF among direct competitors who fulfilled our demand criteria as the basis for making comparisons in pricing strategy. The six graduated positive and six negative price difference categories ranged from less than 1 to 40 per cent above or below the competition. After grouping courses according to their daily pricing differences by customer segment, we calculated the average percentage difference between each course and its competitive set on capacity utilization and RevPATR.

\section{PRICE ELASTICITY FINDINGS}

Using the specified model that includes course characteristics (i.e., age, rating, slope, number of holes, regular tee par, water features, and lodging) and market conditions (i.e., temperature, precipitation, and location) along with a fixed effect for year, we obtained price elasticity coefficients based on 8,412,599 rounds of booked golf during the 3-year time period. Our estimates of the price elasticities were developed by customer segment (package vs. walk-in player types), and course quality competitive tier (Tier 1 lowest quality to Tier 4 highest quality courses), for the time period 2012-2014. We estimated elasticities (1) by customer segment and tier; (2) by customer segment, tier and month; and (3) by customer segment, tier and day of the week. The problem of aggregation bias has been examined in macroeconomics, urban economics, and hotel revenue management.

Demand is price elastic when the coefficient values are less than -1, while values between zero and minus one are deemed price inelastic. Table 1 provides the price elasticities for package and walk-in players by Tier. Notice that the price elasticity estimates in Table 1 are mostly positive, and most values are insignificantly different from zero. As the data reveal, none of the price elasticity estimates is less than -1 , hence demand for golf in this destination market is not price sensitive. The positive and significant values found for package players in tiers 2 through 4 imply that a price increase will result in an increase in the number of rounds of golf booked and in turn result in an increase in revenue. Each of the negative estimates is insignificantly different from zero. 
Table 2 provides a range of price elasticities for package and walk-in player customer segments by month by tier. None of the price elasticities are less than -1 for this destination golf market, revealing that demand for golf is price inelastic. Notable in this study is just how price insensitive demand for golf is in both high season months such as March, April, and May, and low season months such as December, January, and February—regardless of player type and course quality tier. The implication of this finding is that for both package and walk-in players our results show that golf course managers can raise prices and increase revenue. In particular, for the months where the price elasticity is insignificantly different from zero, a price increase will have no significant impact on demand and hence revenue will increase. For the months where the estimate is positive and significant, revenue will also increase. For the month where the estimate is negative and greater than minus one, revenue will increase as a result of a price increase even though demand will fall.

Our final analysis was to explore price elasticities by day of the week, given that demand is likely to be greater on weekends and slower during the week. Table 3 provides the price elasticities by day of the week, for both customer segments (package and walk-in players) and course tier quality. As shown in the results in Table 3, none of the price elasticity estimates are less than -1 , hence none of the days of the week are price elastic in this market, regardless of customer segment or course quality tier. These results support our other findings that the demand for golf is predominately price insensitive by day of week across different tiers. Once again implying that an increase in price will result in an increase in revenue. With all of the elasticity coefficients greater than -1 , we see a pattern of price insensitivity, which has significant implications for both revenue opportunities in this market and a deeper understanding of consumer behavior in a discretionary leisure sport activity such as golf.

Before moving to our second research question about competitive pricing in golf, we did one final analysis to explore daily price elasticities. While the number of elasticities is too numerous to summarize in this paper, our results further confirm our findings. For example, a close look at price elasticities by day for package and walk-in players over the sample period by course quality tier revealed that golf course managers could raise prices 95 per cent of the days of the year for tier 4, to every day of the year 
for tier 2 courses and get higher revenues. For walk-in players, the percentage of days in the year in which demand was price inelastic was 93 per cent for tier 4-98 per cent for tier 1. It is interesting to note from this more fine-grained daily analysis that so few days exist in which demand was estimated as price elastic. Overall, demand for golf in this large destination golf market was insensitive to price. These findings give practitioners in this market substantial opportunities for revenue management and dynamic pricing.

\section{COMPETITIVE PRICING FINDINGS}

To investigate how golf price changes drive golf course utilization and revenue, we began by categorizing the pricing strategy of each golf course into one of twelve groups based on the average daily fee (ADF) paid by the package and walk-in customer segments. These pricing- strategy groups ranged from a category of 30-40 per cent lower than the competitive quality tier of courses to a group that priced 30-40 per cent higher than the competition. We only included in this analysis courses that had daily rounds played within one standard deviation of the average number of rounds played by courses in the same competitive tier to assure we were looking at comparable courses. After grouping golf courses according to their pricing strategies, we graphed the percentage difference in daily capacity utilization and daily RevPATR.

Figure 1 graphs the percentage differences in RevPATR for both customer segments (i.e., walk-in and package) across the price strategy groupings in 2013 of each competitive tier from the lowest tier (Tier 1) to the highest quality courses in the market (Tier 4). Golf courses that priced above their competitive tier experienced higher RevPATR, and the higher they priced their products in both customer segments the greater there gains, with the exception of customers in the package segment of the lowest tier courses, where pricing just a little (less than 5 per cent) above the competitive set yielded the greatest percentage gain. For all course tiers and customer segments, golf courses that priced much lower than their competitive tier had lower RevPATR. According to the data, the maximum revenue benefit was obtained by golf courses that charged rates of over 20 per cent above those of their competitive tier 
(except for Tier 1 package players). The unique pattern found in tier 1 golf courses for package customers may be a function of the customer who seeks out the cheapest courses in the market. It is quite likely that the lowest quality courses attract the most price sensitive customers. Overall, the data revealed that courses that price below their competitive tiers have lower RevPATRs.

The pattern of percentage differences in capacity utilization for both customer segments is shown graphically in Fig. 2. The graph shows a somewhat flat capacity utilization curve across the different pricing categories. This would suggest that capacity does not rise when prices are lowered, again providing support for the finding of price inelasticity. A careful look at each competitive tier and customer segment does suggest some notable differences. In Tier 1 for package players, the greatest percentage differences among competitors' utilization occur when the price differences are the same; however, as courses price below their competitive tier, they are able to secure higher demand. Courses that appeal to package golf customers in Tier 2 and Tier 3 have lower utilization when they price below their competitive sets, suggesting that these price insensitive customers are willing to pay higher prices. For the highest tier golf courses (Tier 4), capacity utilization is strong when the course prices just a little (less than 5 per cent) below the competitive tier. The rising capacity utilization for walk-in customers of Tier 1 golf courses with higher competitive prices, may suggest that typical destination golfers discover they can play lower quality courses at prices lower than the higher tiers, motivating smart lower tier course owners to raise their prices to steal share from higher priced and higher quality courses in the market. Keep in mind that we used a decision rule in examining the courses for this analysis that eliminate courses that were not pricing within one standard deviation of the competitive set, hence excluding courses from the analysis that were pricing way above or way below their competitive tier from inclusion in the analysis.

The maximum capacity utilization advantage over the competitive set differed by customer segment and by competitive tier (see Fig. 2). Interestingly for walk-in customers, courses that price higher than their competitors had higher utilization in tier 1, while the opposite was true for courses in tiers 2 and 4. Tier 3 courses had the highest utilization when they price just a little (less than 5 per cent) above their 
competitive set. For these courses, pricing way below the competitive set yielded lower capacity utilization. For package customers, most of the utilization was stable across pricing strategies. The overall patterns suggested courses that essentially held their prices equivalent to those of their competitive set (that is, dropped or raised their relative prices by small percentages) experienced both strong capacity utilization and RevPATR gains relative to their competitors, although the RevPATR gains were much greater for courses that priced above their competitors.

Figure 3 shows the combined package and walk-in golfers' competitive pricing during the peak season of golf in the month of April in 2013. For this analysis, each golf course was grouped into one of 30 pricing groups based on the average daily fee (ADF) of both package and walk-in customer segments combined. The pattern of RevPATR was very clear during the peak season. Golf courses that priced 2.6 per cent or more below their competitive tier had lower revenues relative to their competitors, while those that priced above their competitors had RevPATR benefits. In keeping with our findings about price elasticity, capacity utilization was relatively stable, even when golf courses priced at lower relative rates. Golf courses that kept their prices higher than those of their competitive tier enjoyed relatively higher capacity utilization up to a point. The courses that priced between 50 and 60 per cent higher than their competitive tier did experience lower capacity utilization.

Again the findings support the result that pricing and capacity utilization are not traded off against each other, suggesting that the purchase decision is discretionary. The patterns in the graphs of both the percentage difference in utilization and RevPATR are similar for different customer segments and peak and overall seasons of the year. Golf courses that charge a price premium have substantially higher RevPATRs than their competitors without reductions in utilization with the exception of the extremely high-priced courses in the peak season. Overall, utilization rose slightly as revenues rose, suggesting that demand for golf is not sensitive to dramatic price reductions. 


\section{CONTRIBUTION/MANAGERIAL IMPLICATIONS}

Our first research question was to empirically estimate the price elasticities of golf course demand in a large golf market in the US. To investigate this question, we built several different models that controlled for both external factors such as the weather, and course characteristics. For inelastic goods, an increase in unit price will tend to increase revenue, while a decrease in price will tend to decrease revenue. Overall our results suggest that demand for golf is price inelastic, which would suggest that golf course owners might be best served by raising their prices to maximize revenue opportunities. Moving from static rates to more flexible pricing is essential if the operators in the market wish to increase their revenues. The general lack of price elasticity by month and day of the week for both package and walk-in players would suggest that golf may be a luxury good in which demand is not as sensitive to price as expected, and that the industry has not effectively explored how to adjust prices based on fluctuations in demand.

Figure 4 shows the number of rounds played by daily tee time, and the fees charged by tee time. This descriptive data from 2013 help us see how demand fluctuates by time of day, while fees are more static. For example, the highest demand time during the day was at 9:00 a.m., with 92,923 rounds of golf played at that time in 2013 at an average tee time fee of $\$ 55.48$; in contrast to the lowest demand tee times at the end of the day with one round of golf played at tee times between 6:17 p.m. and 6:55 p.m. having an average fee of \$52.83. If the golf industry was better at dynamic pricing they would price higher during high demand periods and lower during the shoulder times. Given that our findings show that generally speaking consumer's buying habits remain unchanged as the price of a round of golf goes up or down, we suggest that there are numerous opportunities to raise prices during high demand tee times, days of the week, peak seasons, or special occasions (e.g., father’s day). Operators would be advised to particularly price higher for the high demand tee times around 9:00 in the morning and 1:00 in the afternoon.

Last minute bookings and cancellations are a common phenomenon in the golf industry, and better managing the booking windows might also be a fruitful way to maximize profitability, particularly 
in light of price insensitivity. Figure 5 shows the booking curve for the destination studied. The booking pattern for 2013 shows that 50.8 per cent of all bookings are made within a week of play, with 8.9 per cent booked the same day, 14.2 per cent booked the day before, and 12.4 per cent booked two days before play. The last minute pattern of golf reservation booking suggests that this is a highly discretionary purchase decision for which excess supply or highly flexible demand make it difficult to lift price at the last minute. The capacity utilization lift for lower priced package players in the lowest tier may be oneway owners try to incentivize price sensitive players to book early. As online bookings of golf tee times increase in popularity, lower prices will be easier to locate at the last minute given excess supply in many destination markets, and operators will face even greater reference pricing challenges, in spite of the demand inelasticity found in this study.

In the second research question, we explored the impact on capacity utilization and tee time revenue of pricing above or below the same quality competitive tier. Our findings suggest that golf courses do not appear to steal market share by pricing below their competitors (except for lower quality Tier 1 courses). Golf courses that offer much lower fees often achieved both lower relative capacity utilization and lower RevPATR. In contrast, those with the largest percentage difference in price above the competitive set gained the most in RevPATR and solid utilization up to a point. Those who priced way above their competitors experienced drops in demand. Given price inelasticity, it is interesting to note that there is a natural ceiling, perhaps due to having competitors' reference prices available to golf consumers. Many contend that discounting is a viable strategy to "steal market share," but this approach does not appear to be as viable in the golf industry under conditions of price inelasticity. What we found is that lower comparative prices did not help fill the course. However, pricing way above the competitive set, even in high season, may result in a drop in comparative utilization and revenue per available round. Perhaps in the golf setting, these high-priced competitors serve as a valuable cognitive benchmark for shaping reference pricing.

With the rise in popularity of online tee time booking, the local reference price effect may be replaced with one that is more price than experience focused, potentially eroding price insensitivity, and 
leading to low price practices. While online booking is in its infancy in golf, owners, and managers might best be served by carefully managing their pricing by distribution channel to avoid unintentional signals regarding reference prices.

Our results are consistent with previous studies in the lodging context, and pave the way for the introduction of RM strategies in this neglected context. If demand is not price elastic, golf course owners will need to avoid head to head competition, and seek ways to optimize prices during prime tee times, days of the week, and times of the year. In addition, more work is needed to explore the role of the reference price effect on consumer demand as channels of distribution move online. This study is the beginning of much needed research to help the golf industry more fully understand pricing and how revenue management can help maximize profit. The good news for now is that the golf consumer does not appear to increase or decrease their play based on rising or falling prices. 


\section{Note}

1. See, for examples, one of the original articles on aggregation by Theil (1954), an excellent analysis of aggregation problems when examining local housing markets by Goodman (1998), and the effects of aggregation on hotel revenue forecasting accuracy by Weatherford et al (2001). 


\section{REFERENCES}

Anderson, C., Rasmussen, H., and MacDonald, L. (2005) Competitive pricing with dynamic asymmetric price effects. International Transactions in Operational Research 12(5): 509-525.

Bolton, R. and Shankar, V. (2003) An empirically derived taxonomy of retailer pricing and promotion strategies. Journal of Retailing 79: 213-224.

Chung, K. (2000) Hotel room rate pricing strategy for market share in oligopolistic competition eight year longitudinal study of super deluxe hotels in Seoul. Tourism Management 21(2): 135-145.

Douglass, H. (2014) European golf resort investment: Doing the Rounds, HVS London.

Enz, C. and Canina, L. (2010) Competitive pricing in European hotels. Advances in Hospitality and Leisure 6: 3-25.

Enz, C., Canina, L. and Lomanno, M. (2009) Competitive pricing decisions in uncertain times. Cornell Hospitality Quarterly 50(3): 325-341.

Enz, C., and James, E. (2015) “'Strategic Partnering’’. Golf Business, 21 (5) 49-50.

Espey, M. (1998) Gasoline demand revisited: An international meta-analysis of elasticities. Energy Economics 20:273-295.

Gallego, G. and Hu, M. (2007) Dynamic pricing of perishable assets under competition. Working Paper. New York: USA: Columbia University.

Goodman, A.C. and Thibodeau, T.G. (1998) Housing market segmentation. Journal of Housing Economics 7:121-143.

Greenleaf, E.A. (1995) The impact of reference price effects on the profitability of price promotions, Marketing Science 14(1): 82-104.

Hughes, J., Knittel, C.R., and Sperling, D. (2007) Evidence of a Shift in the Short-Run Price Elasticity of Gasoline Demand. UC Berkeley: Center for the Study of Energy Markets.

Kachanil, S., Oumanar, Y. and Raissi, N. (2014) Dynamic Pricing in the Presence of Competition with Reference Price Effect, Applied Mathematical Sciences 8(74): 3693-3708. 
Kimes, S. and Wirtz J. (2003) Perceived fairness of revenue management in the US golf industry. Journal of Revenue and Pricing Management 1(4): 332-344.

Kimes, S.E. and Schruben, L.W. (2002) Golf course revenue management: A study of tee time intervals. Journal of Revenue and Pricing Management 1(2): 111-120.

Levin, Y., McGill, J. and Nediak, M. (2009) Dynamic pricing in the presence of strategic consumers and oligopolistic competition. Management Science 55(1): 32-46.

Lieberman, W. (2004) Revenue management trends and opportunities. Journal of Revenue and Pricing Management 3(1):91-99.

Licata, J. and Tiger, A. (2010) Revenue management in the golf industry: Focus on throughput and consumer benefits, Journal of Hospitality Marketing \& Management, 19:480-502.

Limehouse, F.F., Melvin, P.C. and McCormick, R.E. (2010) The demand for environmental quality: An application of hedonic pricing in golf. Journal of Sports Economics, 11, 261-286.

Limehouse, F., Maloney, M. and Rotthoff, K. (2012) Peak-load versus discriminatory pricing: Evidence from the golf industry, Review of Industrial Organization 40: 151-165.

Melnikov, S.V. (2015) Dynamic monopoly pricing under the reference price effect. Problems of Economy. 1: 361-365.

Mookherjee, R. and Friesz, T. (2008) Pricing, allocation, and overbooking in dynamic service network competition when demand is uncertain. Production and Operations Management 17(4): 455-474.

Breffni, N.M., Canina, L. and Enz, Cathy A. (2012) “'Strategic price positioning for revenue management: The effects of relative price position and fluctuation on performance.’' Journal of Revenue and Pricing Management .12(3): 1-14.

Perakis, G. and Sood, A. (2006) Competitive multi-period pricing for perishable products: A robust optimization approach. Mathematical Programming 107(1): 295-335.

Rasekh, L. and Li, Y. (2011) Golf course revenue management, Journal of Revenue and Pricing Management 10: 105-111.

Theil, H. (1954) Linear Aggregation of Economic Relations. Amsterdam: North Holland. 
Weatherford, L.R., Kimes, S.E. and Scott, D.A. (2001) Forecasting for hotel revenue management: Testing aggregation against disaggregation. Cornell Hotel and Restaurant Administration Quarterly 42(4): 53-65.

Zhang, T. (2014) Dynamic pricing strategy with internal reference effect and competition. Journal of Emerging Trends in Economics and Management Sciences 5(2): 187-193. 
Table 1. Price elasticity estimates by customer segment and course quality tier 2012-2014

\begin{tabular}{|c|c|c|c|c|}
\hline \multirow[t]{2}{*}{ Customer segment (player type) } & \multicolumn{4}{|c|}{ Elasticity estimates } \\
\hline & Tier 1 & Tier 2 & Tier 3 & Tier 4 \\
\hline Package & 0.2179 & $2.2772 \star \star \star$ & $1.0387 \star \star \star$ & $1.0143 \star \star \star \star$ \\
\hline Walk-in & 0.1790 & -0.0707 & 0.0566 & -0.1542 \\
\hline
\end{tabular}

$\star \star \star$ Denotes significance at the 0.05 level, at least. 
Table 2. Price elasticity estimates by month, tier, and customer segment 2012-2014

\begin{tabular}{lcccc}
\hline Month & Tier 1 & Tier 2 & Tier 3 & Tier 4 \\
\hline Elasticity estimates for package players & & & \\
January & -0.1088 & $0.4165 \star \star \star$ & 0.0703 & 0.0053 \\
February & -0.0188 & $1.0638 \star \star \star$ & $0.2687 \star \star \star$ & 0.0619 \\
March & $-0.2729 \star \star \star$ & $0.6797 \star \star \star$ & $0.2718 \star \star \star$ & -0.2889 \\
April & $-0.4351 \star \star \star$ & $0.6300 \star \star \star$ & $0.2279 \star \star \star$ & 0.1281 \\
May & $-0.3153 \star \star \star$ & $1.0433 \star \star \star$ & $0.3457 \star \star \star$ & -0.0404 \\
June & -0.2481 & 0.3217 & -0.0685 & 0.1538 \\
July & -0.0404 & -0.0053 & -0.1037 & 0.0391 \\
August & -0.2235 & 0.0695 & 0.0101 & -0.1755 \\
September & -0.0638 & $0.9152 \star \star \star$ & 0.1857 & 0.0406 \\
October & 0.0325 & $1.2157 \star \star \star$ & 0.1596 & -0.1762 \\
November & 0.2392 & $1.9868 \star \star \star$ & $0.5150 \star \star \star \star$ & $0.6196 \star \star \star \star$ \\
December & 0.0002 & $1.1560 \star \star \star \star$ & 0.1375 & 0.1785 \\
Elasticity estimates for & walk-in players & & & \\
February & 0.2940 & -0.1269 & -0.2018 & $-0.5443 \star \star \star \star$ \\
March & 0.3509 & $-0.2184 \star \star \star$ & -0.0319 & -0.2176 \\
April & -0.2192 & -0.0751 & 0.0122 & -0.0569 \\
May & -0.1773 & $-0.3782^{\star \star \star \star}$ & -0.1949 & $-0.3091 \star \star \star$ \\
June & -0.4898 & -0.2436 & -0.0066 & -0.3251 \\
July & 0.1047 & -0.0183 & 0.2360 & $-0.4938 \star \star \star$ \\
August & 0.2375 & -0.2483 & 0.3881 & $-0.8695 \star \star \star$ \\
September & -0.0215 & $-0.7394 \star \star \star$ & -0.2771 & -0.3144 \\
October & -0.2104 & -0.2404 & 0.0499 & -0.2657 \\
November & 0.1175 & 0.1316 & -0.2874 & -0.2201 \\
December & 0.0555 & $0.1036 \star \star \star \star$ & -0.0032 & $-0.2943 \star \star \star$ \\
\hline
\end{tabular}

$\star \star \star$ Denotes significance at the 0.05 level, at least. 
Table 3. Price elasticity estimates for day of the week, tier and customer segment 2012-2014.

\begin{tabular}{lcccc}
\hline Day & Tier 1 & Tier 2 & Tier 3 & Tier 4 \\
\hline Elasticity estimates for package players & & & \\
Sunday & $0.3113 \star \star \star$ & $2.0810^{\star \star \star \star}$ & $1.0060^{\star \star \star \star}$ & $1.0719 \star \star \star$ \\
Monday & 0.0771 & $2.0547 \star \star \star$ & $1.0156^{\star \star \star \star}$ & $0.8748^{\star \star \star \star}$ \\
Tuesday & 0.0342 & $2.0153 \star \star \star$ & $0.9774^{\star \star \star \star}$ & $0.8298^{\star \star \star \star}$ \\
Wednesday & 0.0817 & $2.0533^{\star \star \star \star}$ & $1.1439 \star \star \star$ & $0.9136^{\star \star \star \star}$ \\
Thursday & $0.3385 \star \star \star$ & $2.5119 \star \star \star$ & $0.9976 \star \star \star \star$ & $1.0046 \star \star \star$ \\
Friday & 0.2685 & $2.5747 \star \star \star$ & $1.0448^{\star \star \star \star}$ & $1.2221^{\star \star \star \star}$ \\
Saturday & 0.2527 & $2.3729 \star \star \star$ & $1.0186 \star \star \star$ & $1.0609 \star \star \star$ \\
Elasticity estimates for walk-in players & & & \\
Sunday & 0.0826 & -0.0499 & 0.1424 & -0.1948 \\
Monday & 0.0651 & -0.1200 & -0.0980 & -0.2416 \\
Tuesday & 0.2799 & -0.1427 & -0.1128 & -0.2192 \\
Wednesday & 0.1987 & -0.1503 & -0.0202 & -0.1628 \\
Thursday & 0.2800 & -0.1276 & 0.0461 & -0.1607 \\
Friday & 0.3977 & 0.0493 & 0.2323 & -0.0865 \\
Saturday & -0.0066 & $-0.0174 \star \star \star$ & 0.0947 & -0.1253 \\
\hline
\end{tabular}

$\star \star \star$ Denotes significance at the 0.05 level, at least. 
1200

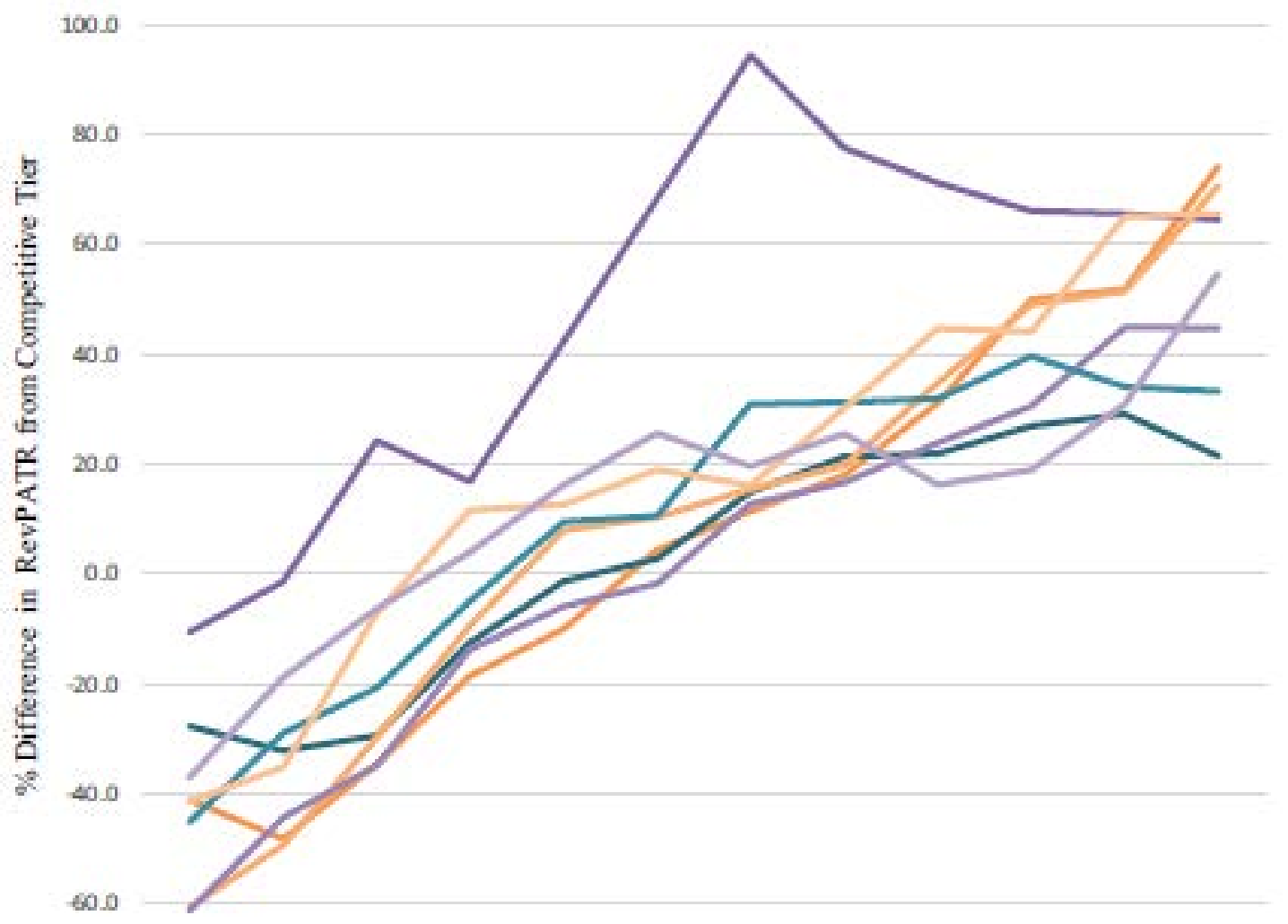

$\%$ Difference in Average Daily Fee (ADF) From Competitive Tier

\begin{tabular}{|c|c|c|c|c|c|c|c|c|c|c|c|c|}
\hline & $-\infty 1.0$ & $-30,0$ & $-20,0$ & -10.0 & -5.0 & 0.0 & 0.0 & 5.0 & 10.0 & 20.0 & 30.0 & 40.0 \\
\hline Tier 1 Walk-in & -41.1 & -48.2 & -34.5 & -18.5 & -10.0 & 4.4 & $11 \mathrm{~A}$ & 17.9 & 31.1 & 50.0 & 51.9 & 74.1 \\
\hline Tier 1 Paclage & -10.6 & -1.4 & 24.2 & 16,8 & 42.3 & 68.3 & 94.3 & 77.5 & 71.1 & 66.0 & 65.5 & 64.4 \\
\hline - Tier 2 Walk-in & -27.6 & -32.1 & -29.4 & -12.5 & -1.3 & 2.8 & 14.9 & 213 & 21.9 & 27.0 & 29.1 & 21.4 \\
\hline Tier 2 Paclage & -60.7 & -493 & -29.7 & -9.4 & 8.0 & 10.4 & 15.5 & 19.7 & 34.7 & 49.1 & 51.3 & 70.5 \\
\hline Tier 3 Walk-in & -61.2 & -4.3 & -34.8 & -13.7 & -5.9 & -1.8 & 12.7 & 16.6 & 23.9 & 30.6 & 44.8 & 44.8 \\
\hline LTier 3 Paclage & -45.1 & -28.9 & -20.7 & -4.9 & 9.5 & 10.6 & 30.9 & 313 & 31.9 & 39.6 & 34,1 & 33,2 \\
\hline$\longrightarrow$ Tier 4 Walk-in & -413 & -35.1 & -7.1 & 11.6 & 12.6 & 19.0 & 16.1 & 30.2 & 44.7 & 44.1 & 65,0 & 65.6 \\
\hline Tier 4 Package & -37.0 & -18.7 & -6.3 & 4.0 & 16.2 & 25.6 & 19.6 & 25.5 & 163 & 18.9 & 30.9 & 54.6 \\
\hline
\end{tabular}

$N=11,701$ for Walk-in rounds of golf

$N=14,060$ for Package rounds of golf

Figure 1. Percentage difference in RevPATR compared to competitor golf courses for package and walkin customer segments in 2013 by competitive tiers. 
100.0

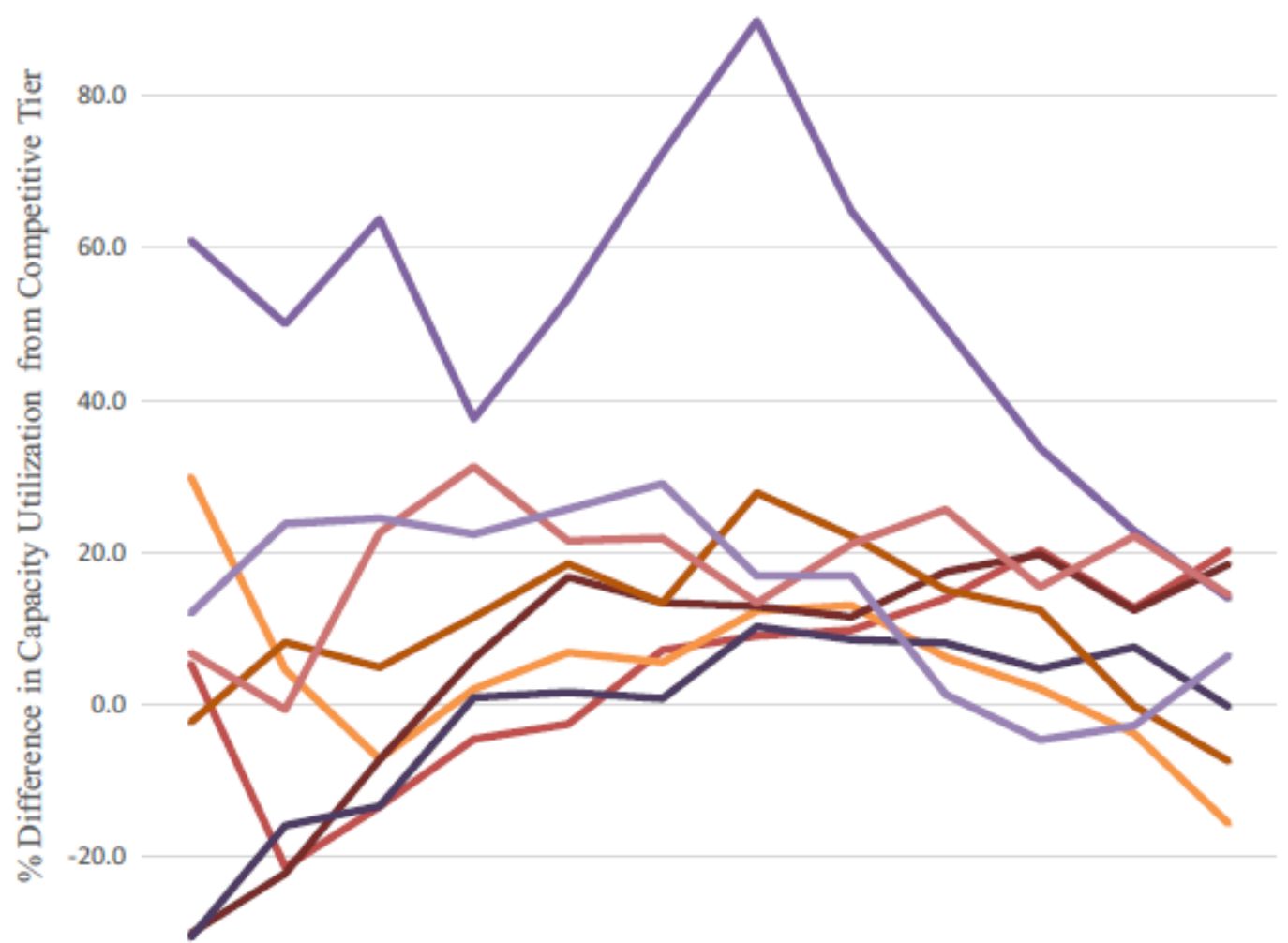

$\%$ Difference in Average Daily Fee (ADF) From Competitive Tier

\begin{tabular}{|c|c|c|c|c|c|c|c|c|c|c|c|c|}
\hline & -40.0 & -30.0 & -20.0 & -10.0 & -5.0 & 0.0 & 0.0 & 5.0 & 10.0 & 20.0 & 30.0 & 40.0 \\
\hline Tier 1 Walk-in & 5.3 & -21.5 & -13.5 & -4.6 & -2.6 & 7.1 & 9.0 & 9.7 & 3.9 & 0.3 & 12.6 & 20.2 \\
\hline Tier 1 Package & 61.0 & 50.0 & 63.8 & 7.5 & .4 & 72.5 & 89.9 & 64.9 & 49.5 & 33.7 & 2.8 & 3.9 \\
\hline 2 Walk-in & 29.9 & & & & & 5.5 & 12.3 & 13.0 & 6.2 & 2.0 & -3.9 & -15.7 \\
\hline -Tier 2 Package & -30.2 & -22.3 & -7.3 & 0 & 16.7 & 13.3 & 12.8 & 11.5 & 17.4 & 19.7 & 12.4 & 18.4 \\
\hline -Tier 3 Walk-in & -30.7 & -16.0 & -13.5 & 0.9 & .5 & 0.7 & 10.2 & 8.5 & 8.0 & 4.6 & 7.5 & -0.4 \\
\hline -Tier 3 Package & -2.4 & 8.1 & 4.8 & 11.5 & 18.4 & 13.3 & 27.8 & 22.1 & 15.0 & 12.3 & -0.3 & -7.5 \\
\hline Tier 4 Walk-in & 6.7 & -0.7 & 22.6 & 31.2 & 21.5 & 21.8 & 13.3 & 21.1 & 25.6 & 15.4 & 22.1 & 14.4 \\
\hline -Tier 4 Package & 12.0 & 23.7 & 24.4 & 22.3 & 25.7 & 29.0 & 16.8 & 16.9 & 1.3 & -4.7 & -2.8 & 6.4 \\
\hline
\end{tabular}

$N=11,701$ for Walk-in rounds of golf

$N=14,060$ for Package rounds of golf

Figure 2. Percentage difference in capacity utilization compared to competitor golf courses for package and walk-in customer segments in 2013 by competitive tiers. 


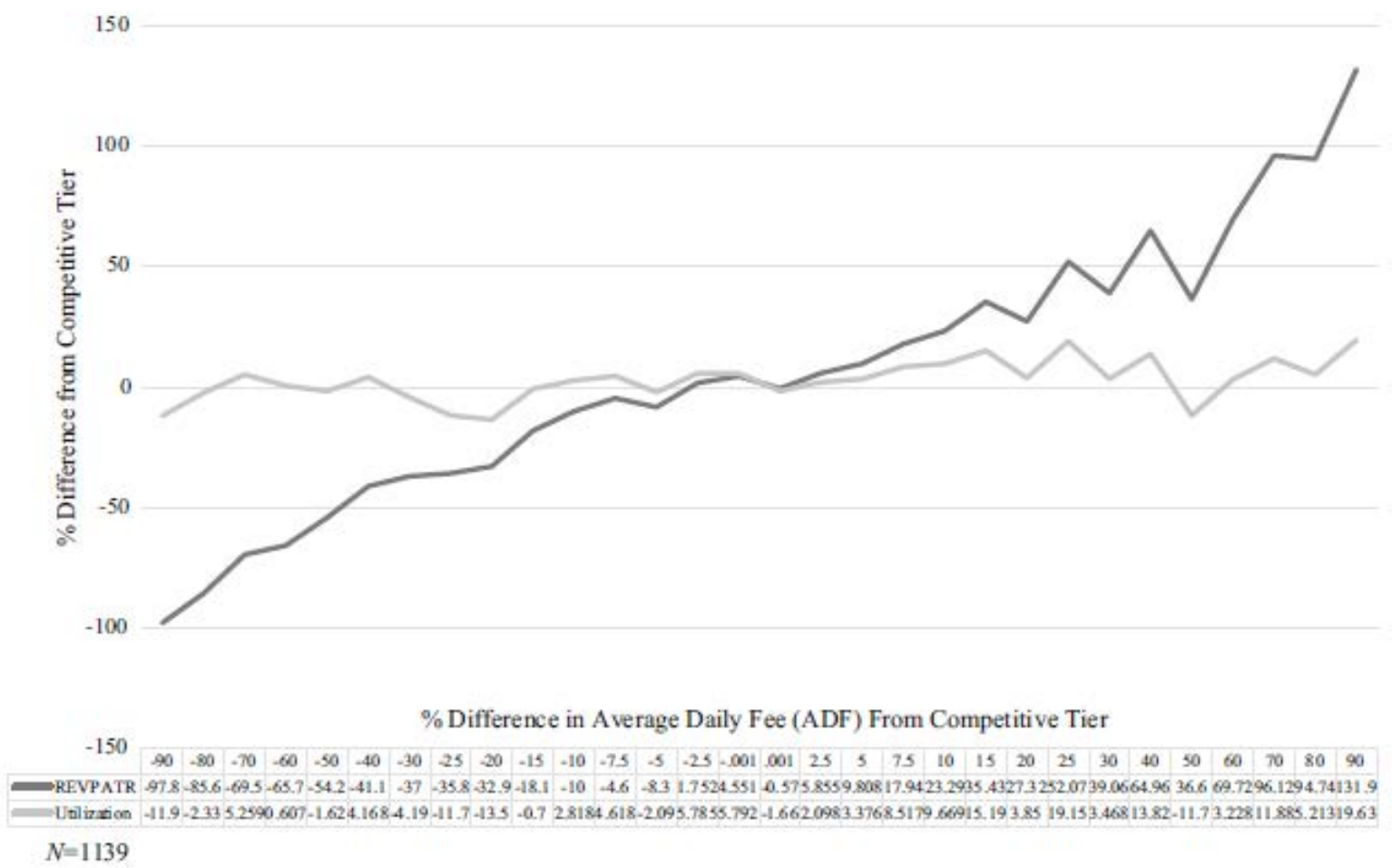

Figure 3: Percentage difference in RevPATR and capacity utilization compared to competitor golf courses in peak season month of April. 


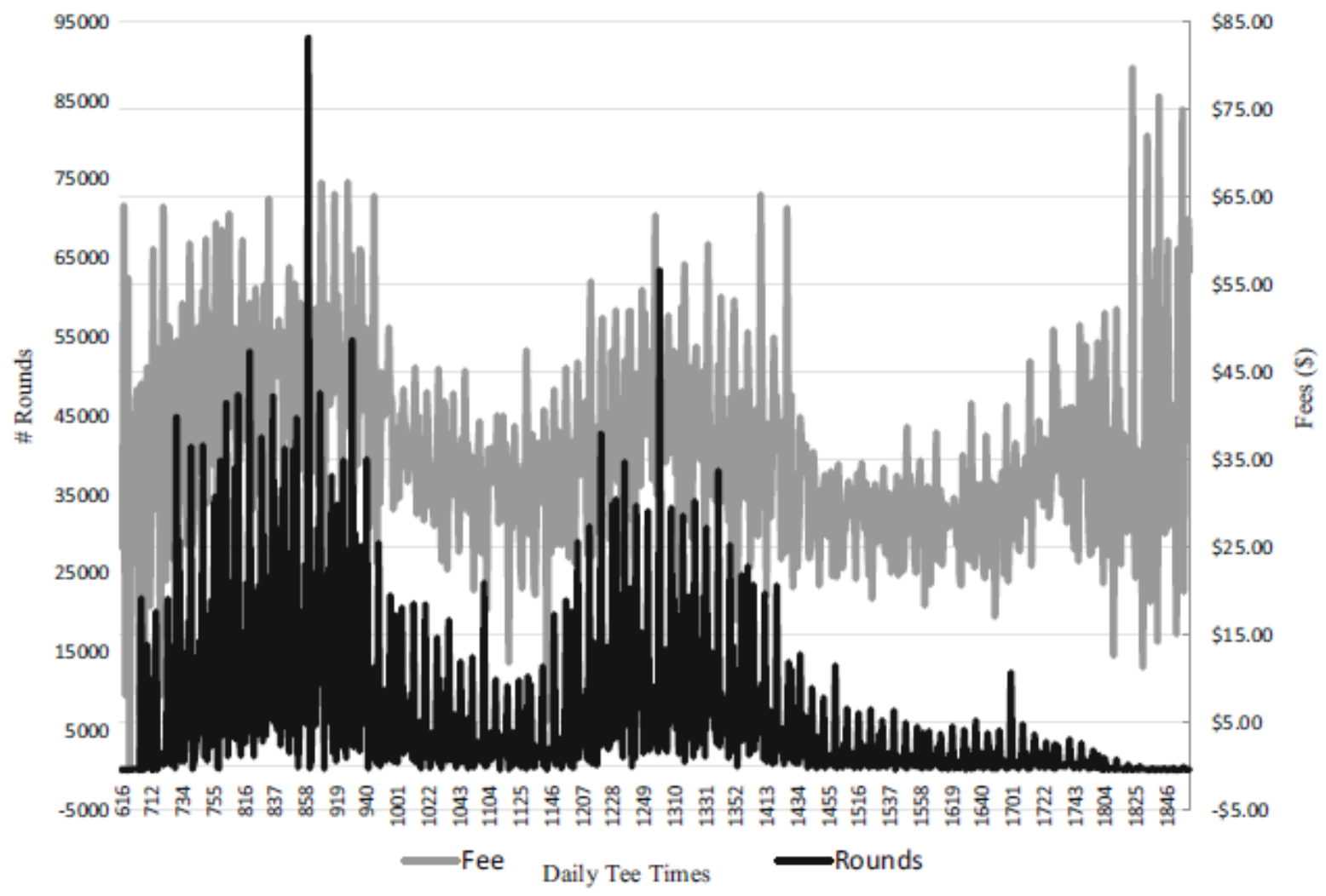

Figure 4: Rounds of golf and fees by daily tee times for 2013. 


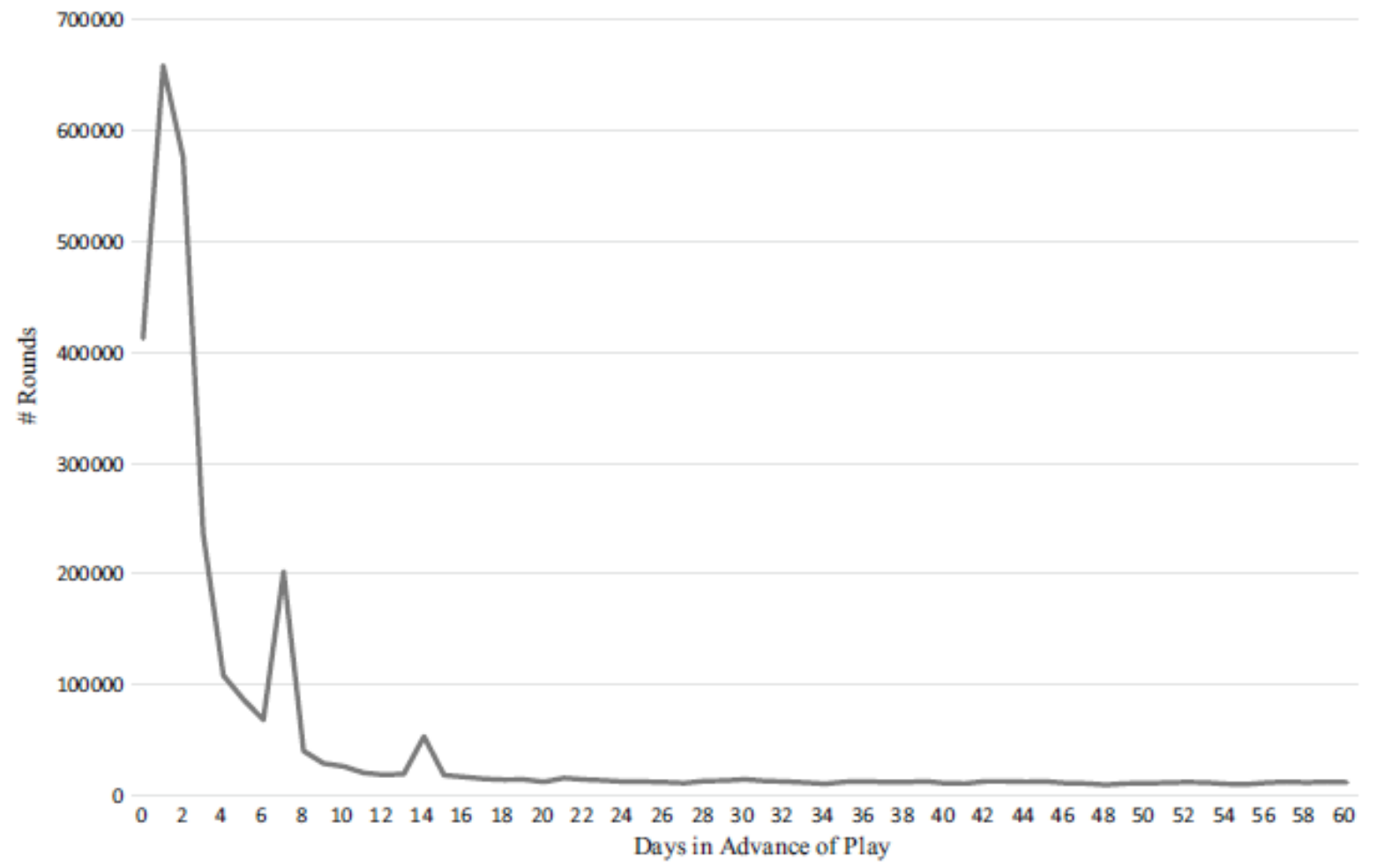

Figure 5: Sixty day booking curve for rounds of golf in 2013. 